\title{
A stakeholder perspective in managing floods in Malaysia
}

\author{
M. Raman, A. O. Ojo \& M. Dorasamy \\ Faculty of Management, Multimedia University, Cyberjaya, Malaysia
}

\begin{abstract}
The recent torrential rains and monsoon rain that hit several states in the East Coast of the Peninsular caused massive flooding, never witnessed in Malaysia before. The sheer catastrophic consequences of the floods were akin to an inland tsunami, as commented by several officials in the country. Official reports and media release estimated that the recent floods would cost Putrajaya and State Governments more than RM 1 billion. Although floods occur annually in Malaysia, there exists a low level of perception about flood disaster risk in Malaysia. This is because many people have considered the prevention and management of natural disaster as one of the government's responsibilities. Nevertheless, individuals are likely to employ different coping strategies in responding to such disasters. This study posits an inclusive approach to disaster risk reduction (DRR) by arguing that the perspectives of those affected by flood are relevant to formulating and implementing DRR strategy. Thus, there is need to understand the factors underlying people's abilities to minimise the impact of disasters and the extent to which they are vulnerable to such disaster. This is expected to support the development of risk communication and reduction strategies that can address the specific need of the affected people. Based on the social psychological perspective, we suggest that resilience is dependent on individual characteristics and community supportive networks. Accordingly, the former is delineated into individual coping strategy and self-efficacy, while the latter is expressed as the individual's perception of social support. Furthermore, vulnerability is proposed as the moderator of the relationship between resilience and the underlying factors. The hypothesized model will be tested with data to be collected from the survey of those affected by the recent flooding across two states in Malaysia (i.e. Kelantan and Pahang).

Keywords: resilience, coping strategy, self-efficacy, social support, vulnerability, Malaysia, flood, disaster risk reduction strategies.
\end{abstract}




\section{Introduction}

With an average annual rainfall of $2500 \mathrm{~mm}$, Malaysia has one of the highest amounts in the world, making the country prone to flooding [1]. Although, unlike the neighbouring countries such as Indonesia and Philippines, which are highly susceptible to coastline flooding associated with tsunamis, Malaysia has mostly experienced monsoon and flash floods. In addition to the heavy rainfall and the effects of global warming, is the rapid urbanisation, which has collectively resulted in the increasing frequency of flooding in Malaysia. The devastating impacts of such transcend the economy, creating huge political and institutional challenges. According to the Malaysian department of Irrigation and Drainage, annually flooding affects more than $22 \%$ of the country's population (i.e. 4.82 million) and about 29000 sq. $\mathrm{km}$ or $9 \%$ of total land area. In addition, an average of RM 915 million is lost annually in Malaysia due to flooding [2]. The most recent flooding, which occurred between 15 December 2014 and 3 January 2015, has been described as a catastrophe and the worst in decades. The devastation was significant within the Northern and Eastern corridor of the Malaysia, resulting in the death of 21 people and evacuation of more than 200 , 000. However, despite the above, there exists a low level of perceptions about flood disaster risk in Malaysia [1]. This is because many people have considered the prevention and management of natural disaster as one of the government responsibilities [2]. Nevertheless, the people are likely to employ different coping strategies in responding to such disasters. These strategies are the ways in which people adjust to disasters and are dependent on the environment, economic status, culture as well as social structure [3].

Social scientists have advanced two main theoretical notions in attempt to explain the management of disaster [4]. The hazard notion is premised on the behavioural antecedents of disasters, which argues that disasters are caused by extreme and rare hazard, thus the risk perceptions of those affected by the disasters are less relevant $[5,6]$. Accordingly, the prescriptive solution based on expert and government interventions are more relevant to risk reduction. In line with this most national policies on disaster management have been structured on a top-down framework, without any consideration for the perspectives and participations of those who are directly affected by the disasters. However, there has been an increasing interest for the vulnerability approach. Proponents argue that disaster is mainly experienced by the marginalized, i.e., those who lack access to the resource and means of protection from the hazard [7, 8]. As a result, their perspectives and participations are essential input in the formulation and implementation of DRR. Given credence to the contributions of the other stakeholders, practitioners have canvassed for a community-based DRR [9-11].

Unlike at the national level, international policy makers have recognized the inclusion of other stakeholders. Asides the Hyogo Framework for Action (HFA) international treaties, several other international institutions like the United Nations International Strategy for Disaster Reduction (UNISDR), World Bank Global Facility for Disaster Reduction and Recovery (GFDRR), as well as other global NGOs have emphasized the need for community-based DRR [4, 12]. 
Even though, these offer more encompassing international policy framework, nevertheless the agreements are non-binding and also does not provide concrete targets applicable to specific national context. In response to the above, this study suggests an inclusive approach to DRR, by demonstrating the significance of engaging the community in flood risk reduction strategy in Malaysia. Thus, contrary to the prescriptive intervention, this study argues that the perspectives of the affected local communities are relevant to formulating and implementing sustainable flood DRR in Malaysia. This study will focus on the people who are directly affected by flood disaster, with a view to understand the factors underlying their abilities to minimise the impact of disasters and the implications of their vulnerability to such disasters. This is expected to support in the development of risk communication and reduction strategies that can address the specific needs of the affected people. Specifically, the main problem that will be addressed by this study is: how grassroots participation could be incorporated in the formulation and implementation of the centrally governed interventions to DRR in Malaysia.

\section{Theoretical background}

Indeed, there has been an increasing in the occurrence of disasters across the globe, thereby suggesting the growing vulnerability of the world [13]. Consequently, the DRR strategies have gained wide acceptability in attempt to address such vulnerability. DRR is the "systematic development and application of polices, strategies and practices to minimise vulnerabilities, hazards and the unfolding of disaster impacts throughout a society, in the broad context of sustainable development" [14, p. 3]. The concept of DRR aligns with the socioeconomic and political perspective on hazard, thereby emphasizing the situated nature of disasters $[8,15-17]$. This is contrary to the traditional notion, which views disasters as unavoidable natural occurrence that can only be managed, as opposed to deploying strategies to support risk reduction $[8,18]$. The success of this strategy is evaluated in terms of the creation of community's resilience, which is the capacity to adapt and maintain an acceptable level of functioning and structure $[19,20]$.

Based on the underlying discipline and mode of investigation, the extant studies on disaster management in Malaysia are examined. Scholarly inquests aligning with the top-down model addresses the role and functions of the government in controlling and managing disaster. The National Security Division, a department under the Prime Minister's office is saddled with coordinating the activities involved in preparing for, preventing, responding to and handling all types of disasters. The NSC is expected to facilitate the appropriate mechanism to ensure that the various agencies collaborating in disaster management fulfil their obligations and also that relief interventions are administered according to the level and complexity of the disaster. In line with this, the committee system is employed at each level of government (i.e. federal, state and district) to enable the participation and coordination of several agencies 
involved in disaster management. This mechanism has been mainly deployed in Malaysia for managing flood disaster and other natural disaster [21, 22].

Following the technocentric model, scholars have examined the role of structural and civil engineering in addressing flood disasters in Malaysia [23, 24]. Related to these are studies based on the natural science perspective, which consider the physical processes in the earth atmosphere system as the main cause of natural hazards. Even though they acknowledged the implications of the society in altering these processes, yet natural phenomenon, which can be technologically managed are considered to be the main causes of natural disaster [2]. The main premise of both approaches is the superiority of the technology in proffering solutions to natural hazards like flood. Although, the implications of technology in the ever changing world cannot be overemphasized, nevertheless, this cannot on its own offer the total protection against all floods. The environment is changing at the rate faster than the necessary technological advancement, thus it has become practically impossible to accurately predict the occurrence and severity of natural disasters like flood. Rather, other soft issues related to the institutions, society, people, and their management and the appreciation of the technology are relevant to DRR.

The organisational perspective to flood disaster management has also gained acceptability in the Malaysian context. The main theoretical premise for this approach is the collective behavioural notion, which emphasis the organisations of various stakeholders like the governmental agencies, private entities, NGOs and the civil society in managing disasters. In essence the organisations have some level of control, which can influence the creation of the capacity for handling hazards. For instance, organisational inefficiencies in terms of cultural gaps and inability to make collective decision could result in blindness and poor information dissemination. However, the bureaucratic nature and secrecy associated with information exchange in most government agencies have been found to negatively impact on efficient emergency planning [25].

In attempt to emphasise the outcome and effect of disasters, the vulnerability model has been suggested. This stemmed from the structural paradigm, wherein disasters are considered to be influenced by the cultural, social, economic and political forces $[8,17]$. The main argument of this perspective is the dominant effects of the structural forces at both the local and national level on the outcome of hazards and disaster, most especially in emerging economy. Based on the structural paradigm, the underlying social factors related to disasters are identified as vulnerability and lack of access to resources. The concept of vulnerability is further to the extant focus on poverty, as depicted in the political economy literature [26]. Rather it suggests an inclusive approach to DRR, by demonstrating the significance of engaging the community in DRR strategy. Therefore, it is able to address the issue of how grassroots participation could be incorporated in the formulation and implementation of the top-down centrally governed interventions to disasters. This is expected to support in the development of risk communication and reduction strategies that can address the specific needs of the affected people. Following this, the study proposes to 
investigate the interaction between the underlying factors of individual's resilience and the implications of vulnerability on this relationship.

\section{Proposed model}

One of the most critical factors underlying effective response to disaster is the clear delineation of the problem and strategies to proffer corresponding solution. In line with this, both academics and practitioners have acknowledged the importance of the disaster risk reduction. The DRR strategy is the systemic approach underlying the effective management disaster risk. The main component of this strategy is the concept of resilience. Holling [27] defined resilience as "a measure of the persistence of systems and of their ability to absorb change and disturbance and still maintain the same relationships between populations or state variables". This concept has been adopted in disaster literature to explain the capacity of an individual or community to bounce back to a functioning state after the occurrence of a disaster [28].

Rather than be helpless in the face of adversity, the community is considered to possess the ability to locate, access and use her internal resources and assets to mitigate the adversity. In addition, adversity and disaster could present an opportunity for the development and growth of the community. Although, such positive outcome associated with disaster does not compensate for the ensuing loss and disruption, nevertheless, it is salient to identify the underlying factors of resilience. Doing this, one could be able to make appropriate intervention that can facilitate the resilience and recovery of the affected.

People respond to disaster in different ways. Some individuals are able to quickly adjust, thereby demonstrating resilience, while others might not be able to recover, thereby being at risk. Several factors have been proposed to account for resilience or risk behaviour in individual. Specifically, the impact of disaster has been conceptualized as a psychologically traumatizing event, with the path to recovery being emotionally stressful [29, 30]. As a result, the occurrence of disaster could trigger psychological impairment, evident in affective and cognitive disturbance. In response, individuals could demonstrate their anger, despair, guilt, helplessness, powerlessness, indecision and confusion, which could collectively result in sustained social disorganisation. The main outcome of disaster is the creation of complex problem requiring the intervention of the individual and community in such a way to positively mitigate the adversity. Thus disaster triggers a change in the individual and collective social life through the reconstruction of individual life-plans and culturally prescribed idealizations. In essence the impact of disaster must be conceptualized from the process underlying individual and community recovery.

Thus, based on the social psychological perspective, this study suggests that resilience is dependent on individual characteristics and community supportive networks [31]. Thus, the former is delineated into individual coping strategy and self-efficacy, while the latter is defined as the individual's perception of social support [32]. Furthermore, vulnerability expressed in terms of individual and 
environmental factors are proposed as the moderator of the relationship between resilience and its underlying factors. The conceptual model is presented in figure 1 .

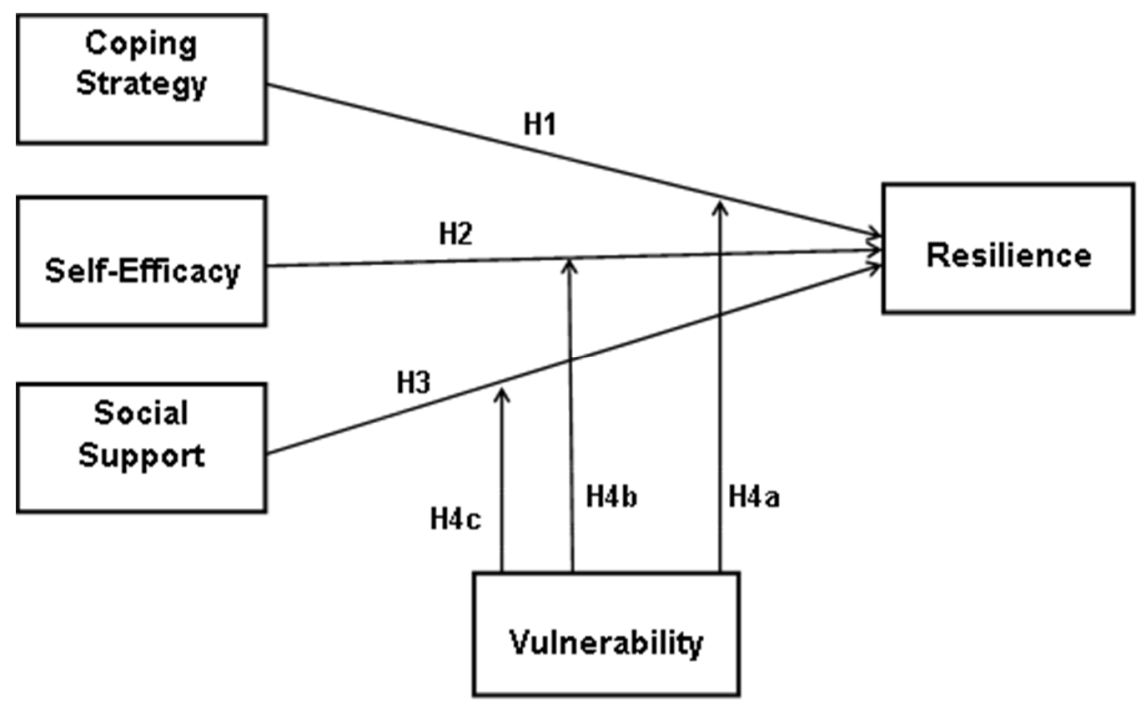

Figure 1: Model for individual resilience in disaster risk reduction.

\subsection{Coping strategies}

The people affected by disaster will strive both individually and collectively to restore normalcy. In doing this, they could become physically, emotionally and socially engaged in the recovery. Thus, in addition to the situational and contextual determinants of resilience, individual's coping strategy is another important underlying factor. The coping strategy could enable an individual to meet the coping demands resulting from a stressful condition. According to Mancini and Bonanno [33], in order to cope in such situation one would need to be strong willed, singly minded and goal focused, which are all elements of pragmatic coping. Clinical research has drawn on the concept of coping strategy in explaining the people abilities to manage with the demand and stress of life $[34,35]$. In adapting to adverse situation, resilient individuals depend on their coping skills. Resilience enables a victim to demonstrate incredible strength when confronted with adversity as well as the capacity to maintain his/her sense of well-being. Based on their coping strategies, individuals are able to effectively manage the stressful situation. Accordingly, such situation could be transformed into less stressful, thereby enabling them to gain some level of influence over their reaction to uncontrollable events [36]. Individuals coping strategies could impact their capacity to bounce back after a major disaster. Thus we hypothesize that:

H1: Individual coping strategy is related to individual resilience to flood disaster. 


\subsection{Self efficacy}

Given the underlying competence and mastery motivation system, individuals are driven to adapt to the environment and gain the benefit of the perceived success [37]. Individuals have the sense of self-awareness, which enable them to exhibit their own agency in adapting to adversity and also perceive the associated benefit. This disposition has been captured through the concept of self-efficacy [38]. The outcome of experimental assessment by Bandura [38] revealed that positive perception of self-efficacy could enable an individual to commit the effort needed for survival, thereby facilitating the ability to persist in adversity. The likeliness of success is deepened through persistence, thus such could reinforce the capacity to adapt. Psychologists have found that the capacity to overcome adversity is closely related to self-efficacy as well as other sense of effectiveness and self-worth [39]. According the following hypothesis is suggested:

$\mathrm{H} 2$ : Individual self-efficacy is related to individual resilience to flood disaster.

\subsection{Social support}

The social support is the level of interactions that enables individual to access and integrate into a web of social relationships that is perceived as loving, caring and timely in when needed [40]. The perceived social support is the belief that help would be available if needed, while the received support is the actual help that is offered at the time of need. The latter follows a mobilization pattern, which increases after the occurrence of the disasters and closely rated to the level of exposure. It also compensate for the former, which in turn influence the mental health [41]. Hogan et al. [42] corroborated that the social support should be reciprocated, wherein the level of received support should be balanced with the provided support. This is also related to the social influence of the support. When faced with disasters people rely on others going through similar experience with them for support. For example, individuals with stronger social support have been found to be able to quickly respond to evacuation notice in the case of Hurricanes Hugo and Andrew [43]. Therefore, an individual's social ties could impact on his/her ability to get back to state of normalcy. Thus, we hypothesize that:

H3: Social support is related to individual resilience to flood disaster

\subsection{Vulnerability}

Vulnerability explains the susceptibility of a system to the occurrence of disaster. In essence it acknowledges the condition of a society, which can turn hazard to disaster [44]. This condition includes the structural constraint like economic and resource inequalities, as well as other exogenous parameters like political systems and governance. As noted by Johnston [32] effective risk disaster communication and reduction strategies should be built on identified vulnerability factors and there likely impact. Since the vulnerability factors are external to the affected people, they are expected to demonstrate the 
proportionate capacities to mitigate the occurrence. These capacities are the resources and assets that enable the people to face and recover from the aftermath of disaster. In addition to the availability of these resources, capacity also includes the ability to apply and access such [45]. Accordingly, individual's level of vulnerability could interact with his/her capacity to resist the disaster. For instance, the ability of the more vulnerable people to access or deploy the needed resource to resist the impact of disaster could be curtained as compared to the less vulnerable. Given the above, we hypothesize that:

H4a: The extent of vulnerability moderates the relationship between coping strategy and individual resilience to flood disaster.

H4b: The extent of vulnerability moderates the relationship between self-efficacy and individual resilience to flood disaster

H4c: The extent of vulnerability moderates the relationship between social support and individual resilience to flood disaster

\section{Conclusion}

The proposed model has implications for the conceptualisation and implementation of risk reduction strategies. According to the model, the people should be motivated to prepare for the occurrence of flood disaster, facilitate the creation of social interaction and ensuring the protection of the vulnerable people. The emergency response strategies should also allow for the participation and engagement of the community in order to facilitate people's ownership of the intervention. Doing this could impact on individual's self-efficacy and willingness to adjust, thereby facilitating the coping skills. Furthermore, the risk communication strategies should ensure the provision of adequate information and mechanism for its dissemination, in order to deepen the social ties among the affected people.

\section{References}

[1] Khalid, M. S. \& Shafiai, S., Flood disaster management in Malaysia: An evaluation of the effectiveness flood delivery system. International Journal of Social Science and Humanity, 5(4), pp. 398-402, 2015.

[2] Chan, N. W., Impacts of disasters and disasters risk management in Malaysia: The case of floods (Chapter 14). Economic and Welfare Impacts of Disasters in East Asia and Policy Responses, eds. Y. Sawada \& Oum S., ERIA Research Project Report 2011-8: Jakarta, pp. 503-551, 2012.

[3] Takeuchi, K., Increasing vulnerability to extreme floods and societal needs of hydrological forecasting. Hydrological Sciences Journal, 46, pp. 869881, 2001.

[4] Gaillard, J.C. \& Mercer, J., From knowledge to action: Bridging gaps in disaster risk reduction. Progress in Human Geography, 37(1), pp. 93-114, 2012. 
[5] Burton I., Kates R. W., \& White G. F. The Environment as Hazard, Oxford University Press: New York, 1978.

[6] Kates, R. W. Natural hazard in human ecological perspective: hypotheses and models. Economic Geography, 47(3), pp. 438-451, 1971.

[7] Hewitt K., The idea of calamity in a technocratic age. Interpretation of Calamities: The Risks and Hazards Series No. 1, ed. K. Hewitt, Allen \& Unwin Inc: Boston, pp. 3-32, 1983.

[8] Wisner B., Assessment of capability and vulnerability. Mapping Vulnerability: Disasters, Development, and People, eds. G. Bankoff, G. Frerks \& D. Hilhorst, Earthscan: London, pp. 183-193, 2004.

[9] Delica-Willison Z. \& Gaillard J. C., Community action and disaster. Handbook of Hazards and Disaster Risk Reduction, eds. B. Wisner, J. C. Gaillard \& I. Kelman, Routledge: London, pp. 669-680, 2012.

[10] Heijmans A., The social life of community-based disaster risk management: Origins, politics and framing policies. Working paper No. 20, Aon Benfield UCL Hazard Research Centre London, 2009.

[11] Pelling M., The Vulnerabilities of Cities: Natural Disasters and Social Resilience. Earthscan: London, 2003.

[12] Jessop B., The crisis of the national spatiotemporal fix and the tendential ecological dominance of global capitalism. International Journal of Urban and Regional Research, 24, pp. 323-360, 2000.

[13] United Nations International Strategy for Disaster Reduction (UNISDR), Reducing vulnerability and exposure to disasters. The Asia-Pacific Disaster Report, 2012. http://www.unisdr.org/files/29288 apdrexecsummary.pdf

[14] United Nations International Strategy for Disaster Reduction (UNISDR). 2004. Terminology: Basic Terms of Disaster Risk Reduction. UNISDR: Geneva.

[15] Torry, W. I., Anthropological Studies in Hazardous Environments: Past Trends and New Horizons. Current Anthropology, 20, pp. 517-40, 1979

[16] Hewitt, K., Preventable disasters: addressing social vulnerability, institutional risk, and civil ethics. Geographische Rundscahu, International Edition, 3(1), pp. 43-52, 2007.

[17] Gaillard, J. C., Resilience of traditional societies in facing natural hazards. Disaster Prevention and Management, 16(4), pp. 522-544, 2007.

[18] Bankoff, G., Rendering the world unsafe: 'vulnerability' as western discourse. Disasters, 25(1), pp. 19-35, 2001.

[19] Department for International Development (DFID), Disaster risk reduction: A development concern. DFID: London, 2005.

[20] Mercer J., Disaster risk reduction or climate change adaptation: Are we reinventing the wheel? Journal of International Development, 22(2), pp. 247-264, 2010.

[21] Chan, N. W., Addressing flood hazards via environmental humanities in Malaysia. Malaysian Journal of Environmental Management, 12(2), pp. 11-22, 2011. 
[22] Aini, M. S., Fakhru'l-Razi, A. \& Daud, M., Evolution of Emergency Management in Malaysia. Journal of Contingencies and Crises Management 9(1), pp. 46-53, 2001.

[23] Ab. Ghani, A., Chang, C. K., Leow, C. S. \& Zakaria, N. A., Sungai Pahang Digital Flood Mapping: 2007 Flood. International Journal of River Basin Management, 10(2), pp. 1-10, 2012.

[24] Julien, P. Y., Ab. Ghani, N. A., Abdullah R. \& Chang C. K., Case Study: Flood Mitigation of the Muda River. Malaysia, Journal of Hydraulic Engineering, 136(4), pp. 251-261, 2010.

[25] Handmer, J. W. \& Parker, D. J., British disaster planning and management: An initial assessment. Flood Hazard Research Centre, Publication 202: Enfield, 1991.

[26] Blaikie, P., Cannon, T., Davis I. \& Wisner, B., At risk: natural hazards, peoples' vulnerability and disasters. Routledge: London, 1994.

[27] Holling, C., Resilience and stability of ecological systems. Annual Review of Ecology and Systematics, 4, pp. 1-23, 1973.

[28] Norris, F. H., Stevens, S. P., Pfefferbaum, B., Wyche, K. F. \& Pfefferbaum, R. L., American Journal of Community Psychology, 41, pp. 127-150, 2008.

[29] Cohen, R. E. \& Ahearn, F. L., Handbook for mental care of disaster victims. John Hopkins University Press: Baltimore, 1980.

[30] Gleser, G. C., Green, B. L. \& Winget, C., Prolonged psychosocial effects of disaster: A study of Buffalo Creek, Academic Press: New York, 1981.

[31] Violanti, J.M., Paton, D. and Dunning C., Post-traumatic stress intervention: Challenges, issues and perspectives, Charles C. Thomas, Springfield, IL, 2000.

[32] Johnston, D.P.D., Disasters and communities: vulnerability, resilience and preparedness. Disaster Prevention and Management: An International Journal, 10(4), pp. 270-277, 2001.

[33] Mancini, A.D. \& Bonanno, G. A., Predictors and parameters of resilience to loss: Toward an individual differences model. Journal of Personality, 77(6), pp. 1805-1832, 2009.

[34] Wong, D. F. K., Stage-specific and culture-specific coping strategies used by mainland Chinese immigrants during resettlement in Hong Kong: A qualitative analysis. Social Work Health and Mental Health, 35(1/2), pp. 479-499, 2002.

[35] Aroina, K. J., \& Norris, A. E., Resilience, stress and depression among Russian immigrants to Israel. Western Journal of Nursing Research, 22(1), pp. 54-67, 2000.

[36] Bernardes, C. M. S., Ray, S. \& Harkins, D., An Exploratory Study of Resilience and Coping Strategies among Portuguese-Speaking Immigrant Women Survivors of Domestic Violence. American Journal of Psychological Research, 5(1), pp. 81-96, 2009.

[37] White, R., Motivation reconsidered: the concept of competence. Psychological Review, 66, pp. 297-333, 1959. 
[38] Bandura, A., Self-efficacy: the exercise of control. Freeman: New York, 1997.

[39] Hauser, S. T., Allen, J. P. \& Golden, E., Out of the woods: tales of resilient teens. Harvard University Press: Cambridge, Massachusetts, 2006.

[40] Barrera, M., Jr., Distinctions between social support concepts, measures, and models. American Journal of Community Psychology, 14, pp. 413445, 1986.

[41] Norris, F.H., \& Kaniasty, K., Received and perceived social support in times of stress: A test of the social support deterioration deterrence model. Journal of Personality and Social Psychology, 71, pp. 498-511, 1996.

[42] Hogan, B. E., Linden, W., \& Najarian, B., Social support interventions: Do they work? Clinical Psychology Review, 22, pp. 381-440, 2002.

[43] Riad, J., Norris, F., \& Ruback, R. B., Predicting evacuation in two major disasters: Risk perceptions, social influence, and access to resources. Journal of Applied Social Psychology, 29, pp. 918-934, 1999.

[44] Cannon, T., Vulnerability analysis and the explanation of natural disasters. Disasters, development and Environment, ed. A. Varley, John Wiley \& Sons: New York, pp. 13-29, 1994.

[45] Davis, I., Progress in Analysis of Social Vulnerability and Capacity. Mapping vulnerability: Disasters, Development \& People, eds. G. Bankoff, G. Frerks, and D. Hilhorst, Earthscan: London, pp. 128-144, 2004. 